\title{
Prevalence and Factors Associated with Musculoskeletal Pain among Dentists in Chandigarh: A Cross Sectional Study
}

\author{
Humanshi Abbhi' ${ }^{1}$ Pradip Sarkar ${ }^{1}$, Hariharan Ramasubbu' ${ }^{1}$, Sombir Singh ${ }^{2}$, \\ Satinder Pal Singh ${ }^{3}$, Mandeep Singh Dhillon ${ }^{4}$
}

\author{
${ }^{1}$ Department of Physical \& Rehabilitation Medicine, PGIMER, Chandigarh, India. \\ ${ }^{2}$ Senior Resident, Department of Oral Health Sciences, PGIMER, Chandigarh, India. \\ ${ }^{3}$ Professor of Department of Oral Health Sciences, PGIMER, Chandigarh, India. \\ ${ }^{4}$ Professor and HOD of Department of Orthopaedic Surgery and Department of Physical and Rehabilitation \\ Medicine, PGIMER, Chandigarh, India.
}

Corresponding Author: Humanshi Abbhi

\begin{abstract}
Background: Dental specialists are at a higher risk of work-related musculoskeletal disorders (WMSD) that lead to physical disability. Musculoskeletal pain in dentists is due to constrained body postures for prolonged period of time. Limited number of studies has been done in India to check the prevalence and factors associated with the musculoskeletal pain among dentists.

Purpose: To see the prevalence and assess the intensity of musculoskeletal pain in different anatomical parts among dentists from two different institutes of Chandigarh along with identification of selected factors associated with the onset of musculoskeletal (MS) pain among them.

Methods: A cross-sectional study was made among interns, postgraduate students and faculty members from two different institutes of Chandigarh. A total of 120 members completed a questionnaire containing 24 questions. The study variables in the questionnaire were divided into 3 groups as: Socio-demographic information, ergonomic variables and work- related musculoskeletal pain.

Results: Most of the dentists (79.2\%) reported musculoskeletal pain during the past 12 months. On comparing different locations of pain, the lower back region was frequently affected area (87.4\%) followed by pain in neck region (83.2\%). Females were more susceptible to pain than males. A significant association $(p<0.05)$ was found between sitting posture adopted by dentists, years of practice and the MS pain. Highest prevalence was found in dentists adopting forward bent posture in sitting during work (87.3\%) and those working for $>15$ years $(90.9 \%)$.

Conclusion: The study revealed that prevalence of musculoskeletal pain was high among dentists. Higher incidence of pain was found in women and younger dentists. The lower back region was most commonly affected area followed by neck region. The study also found that musculoskeletal pain increased with increase in years of practice with significant association between them.
\end{abstract}

Keywords: Musculoskeletal pain, Socio-demographic information, Ergonomic variables

\section{INTRODUCTION}

Dentists have musculoskeletal problems as a standout amongst the most predominant world related dangers due to static stances of long length which is a mandate for dentistry ${ }^{(1)}$. Musculoskeletal
(MS) side effects lead to uneasiness, handicap and torment fundamentally in the neck or lower back known to be exaggerated by sustaining constrained body postures for prolonged period of time ${ }^{(2)}$. Fifty five percent of the MS disorders are 
evaluated to be work-related ${ }^{(3)}$. MS issues are viewed as one of the commonest reasons for business related inability among laborers. Among drug specialists, dental collaborators and representatives, dental specialists have been found to have a higher frequency of musculoskeletal disorders and back pain.

Dental specialist's job requires prolonged sitting and twisting forward, stretching shoulders while treating patients keeps on fueling back agony. The procedures carried out are lengthy because of expanded patient desires and one ends up sitting for prolonged period of time. This is especially unfavorable as it causes shortness of the hip flexors and also inhibits the gluteus muscles which are in lengthened position for prolonged period. It also prompts muscles of the lower back carrying out the responsibility for the gluteus to develop trigger focuses in these synergist muscles to cause lower back torment.

Several other risk factors contributing to development of MS disorders include repetitions, vibrations, forceful exertion, poorly designed equipment workstation, improper work habits, physical/mental stress and poor lighting. Personal characteristics such as gender, height, poor fitness level, insufficient rest periods, physical inactivity during leisure can also increase the risk of developing MS disorders (4) (5). Although occasional pain or discomfort is not a cause of alarm but if regularly occurring pain or discomfort is ignored, the cumulative physiological damage can lead to injury or a career-ending disability ${ }^{(6)}$. MS disorders are considered to be the most common reason (29.3\%) for early retirement age of dentists worldwide. Therefore, all these factors need to be studied simultaneously in order to bring into account their appreciable impact on the musculoskeletal symptoms and help to study ergonomic recommendations for the dental profession.

The incidence of MS pain among dentists is very high therefore; a detailed survey on the occurrence of MS pain paves the way for prevention and intervention strategies. Thus, the study was conducted with the following objectives:

1. To see the prevalence of MS pain in different anatomical parts among dentists from two different institutes of Chandigarh.

2. To assess the intensity of MS pain in different anatomical locations.

3. To identify selected factors associated with the onset of MS pain among them.

\section{MATERIALS AND METHODS}

Study Design: Cross sectional study (survey), descriptive type.

Sampling Method: Convenient Sampling. Sample Size: 120 dentists meeting the eligibility criteria.

\section{Inclusion Criteria:}

- Faculties and Postgraduate students from different specialties (Oral and Maxillofacial surgery, Pedodontics, Orthodontics, Periodontics, Endodontics, Prosthodontics)

- Interns

\section{Exclusion Criteria:}

- Undergraduate students

\section{PROCEDURE}

Two different institutes of Chandigarh, The Department of Oral Health Sciences, Postgraduate Institute of Medical Education \& Research, Chandigarh (PGIMER) and The Dr. Harvansh Singh Judge Institute of Dental Sciences and Hospital, Panjab University, Chandigarh were visited for the survey. Consent was taken from the heads of the respective institutes. Questionnaires along with consent form were distributed among interns, postgraduate students and faculty members from different graduate programs. The purpose and the outcome of the study were explained to the subjects. They were explained how to fill the questionnaire and consent was taken from them. They were given the time of one week to fill the questionnaire. A self - administered 
questionnaire was used containing 24 questions that were validated prior by a pilot study done among 12 dentists. The study variables in the questionnaire were divided into three categories as: Socio-demographic information, ergonomic variables and workrelated musculoskeletal pain. Sociodemographic information included age, gender, type and duration of professional practice. Ergonomic category included dominant limbs, weight and height, characteristics of dental stool and chair, working position, working with or without assistance, posture adopted during work. Work-related musculoskeletal pain category included location and intensity of pain, sick leaves taken, activity preferred to get some relief from pain, kind of activity affected, any treatment taken, physical activity and workload. Informed consent was mandatory and they were allowed to leave the study if at all they wanted. Everyone completed the questionnaire designed and the observations were recorded.

\section{Statistical analysis:}

Descriptive statistics were used to estimate the prevalence of work-related musculoskeletal and demographic characteristics. Chi-square test was also used to assess relationships. The results were considered significant at $p<0.05$. The statistical analysis was done using the Graph
Pad Prism statistical software version 5.

\section{RESULTS AND DISCUSSION}

The questionnaire was completed by 120 professionals including 90 students and 30 faculty members. Considering the sociodemographic variables, the age range of professionals varied between 21-46 years with an average age of 26.46 years (Fig.1.). Among total professionals, $64.2 \%$ were females. Most of the dentists among the participants were without any specialization (51.7\%) and remaining belonged to different specializations like Orthodontics, Pedodontics, Prosthodontics, Periodontics, Endodontics and Oral and maxillofacial surgery (Fig. 2.).

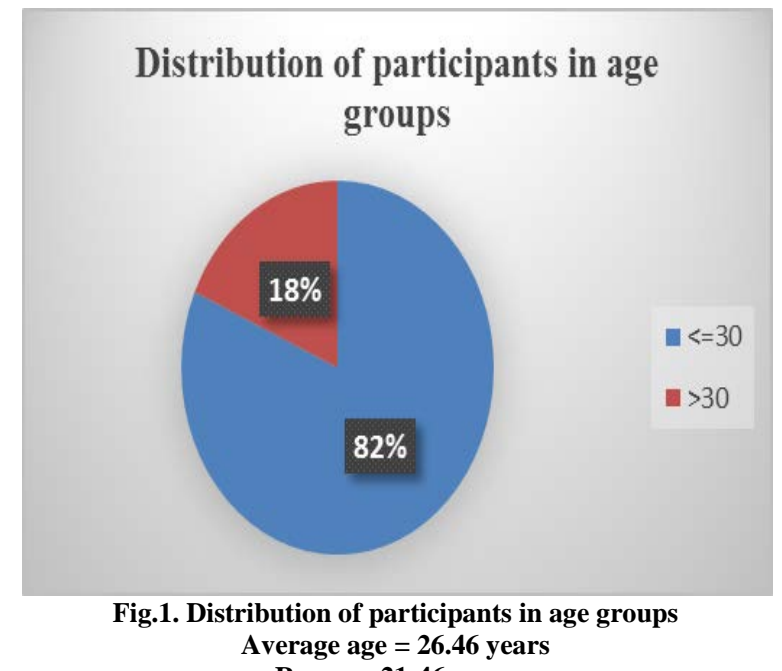

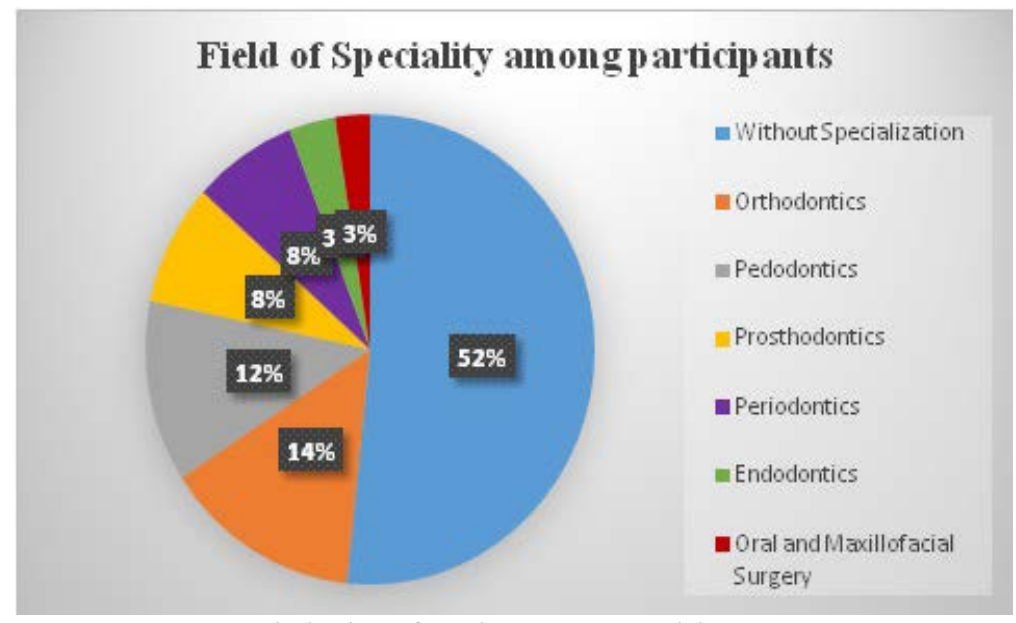

Fig.2. Field of specialty among participants

Considering the ergonomic factors, almost all of the subjects were right-handed
(99.2\%) and $89.2 \%$ of the subjects used indirect vision. Only $25.8 \%$ of the dentists 
Humanshi Abbhi et.al. Prevalence and factors associated with musculoskeletal pain among dentists in Chandigarh: a cross sectional study.

claimed to work with assistance. Majority of the dentists (96\%) used chair with a back rest. A remarkable percent of dentists (55.8\%) adopted sitting position, most of them adopted forward bent sitting position (52.5\%) while only $28.3 \%$ of the dentists alternate their position while working (Fig.3.). Approximately, 72\% of the dentists kept their wrist in neutral position while working and 54\% of them kept their hip and knee bent at more than $90^{\circ}$. As per the study results, $38 \%$ percent of dentists worked continuously for $1-2$ hours, $29 \%$ of them worked for 2-3 hours. More than half of the dentists (58.3\%) claimed that they were aware of ergonomics in dentistry.

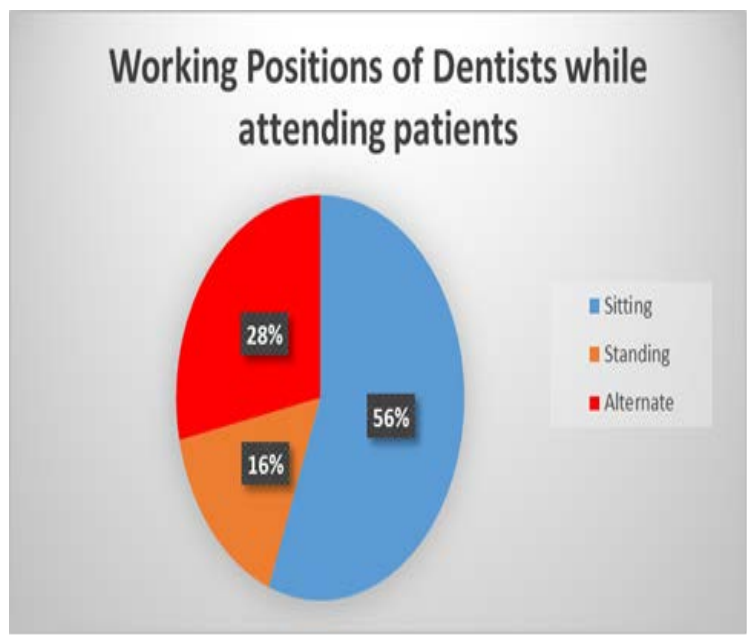

Fig.3. Distribution of subjects in groups according to their working position

Table 1. Prevalence and Intensity of pain according to anatomical locations

\begin{tabular}{|c|c|c|c|c|c|c|c|c|}
\hline S.No. & Location & Gender & $\begin{array}{l}\text { Mean } \\
(0-100)\end{array}$ & Professionals with pain & $\begin{array}{l}\text { Mean } \\
(0-100)\end{array}$ & $\begin{array}{c}\text { Mild } \\
(\%)\end{array}$ & $\begin{array}{l}\text { Moderate } \\
(\%)\end{array}$ & $\begin{array}{l}\begin{array}{l}\text { Severe } \\
(\%)\end{array} \\
\end{array}$ \\
\hline \multirow[t]{2}{*}{1.} & \multirow[t]{2}{*}{ Cervical } & Male & 2.57 & \multirow{2}{*}{83.2} & \multirow{2}{*}{2.95} & \multirow{2}{*}{38.9} & \multirow{2}{*}{40} & \multirow{2}{*}{4.2} \\
\hline & & Female & 3.12 & & & & & \\
\hline \multirow[t]{2}{*}{2.} & \multirow[t]{2}{*}{ Upper back } & Male & 2.67 & \multirow{2}{*}{80} & \multirow{2}{*}{2.87} & \multirow{2}{*}{40} & \multirow{2}{*}{33.7} & \multirow{2}{*}{6.3} \\
\hline & & Female & 2.97 & & & & & \\
\hline \multirow[t]{2}{*}{3.} & \multirow[t]{2}{*}{ Lower back } & Male & 3.90 & \multirow{2}{*}{87.4} & \multirow{2}{*}{3.63} & \multirow{2}{*}{37.9} & \multirow{2}{*}{36.8} & \multirow{2}{*}{12.6} \\
\hline & & Female & 3.51 & & & & & \\
\hline \multirow[t]{2}{*}{4.} & \multirow[t]{2}{*}{ Right lower limb } & Male & 1.60 & \multirow{2}{*}{52.60} & \multirow{2}{*}{1.71} & \multirow{2}{*}{34.7} & \multirow{2}{*}{12.6} & \multirow{2}{*}{5.3} \\
\hline & & Female & 1.75 & & & & & \\
\hline \multirow[t]{2}{*}{5.} & \multirow[t]{2}{*}{ Left lower limb } & Male & 1.23 & & & & & \\
\hline & & Female & 1.42 & 42.1 & 1.36 & 25.3 & 14.7 & 2.1 \\
\hline 6. & Right shoulder & Male & 2.33 & & & & & \\
\hline & & Female & 2.20 & 70.5 & 2.24 & 48.4 & 17.9 & 4.2 \\
\hline 7. & Left shoulder & Male & 1.43 & 579 & & & & \\
\hline & & Female & 1.85 & 57.9 & 1.72 & 41.1 & 15.8 & 1.1 \\
\hline 8. & Right elbow & Male & 0.70 & 370 & 088 & 305 & 74 & 0 \\
\hline & & Female & 0.97 & 37.9 & 0.88 & 30.5 & 1.4 & 0 \\
\hline 9. & Left elbow & Male & 0.53 & 379 & 081 & 316 & 63 & 0 \\
\hline & & Female & 0.94 & 37.9 & & 31.0 & & \\
\hline 10. & Right wrist & Male & 1.03 & 474 & & & & \\
\hline & & Female & 1.38 & 47.4 & 1.27 & 35.8 & 11.6 & 0 \\
\hline 11. & Left wrist & Male & 0.87 & & & & & \\
\hline & & Female & 1.06 & 41.1 & 1.00 & 34.7 & 6.3 & 0 \\
\hline 12. & Right hand & Male & 1.03 & & 124 & 347 & 126 & 0 \\
\hline & & Female & 1.34 & 47.4 & 1.24 & 34.7 & 12.6 & 0 \\
\hline 13. & Left hand & Male & 0.50 & & & & & \\
\hline & & Female & 0.91 & 34.7 & 0.78 & 30.5 & 4.2 & 0 \\
\hline 14. & Headache & Male & 2.63 & $c 0-5$ & 207 & 704 & 77 & 127 \\
\hline & & Female & 3.28 & 69.5 & 3.07 & 28.4 & 27.4 & 13.7 \\
\hline
\end{tabular}

In consideration to MS pain in different anatomical locations, $79.2 \%$ of the participants suffered during the past 12 months. The lower back region was the most affected area (87.4\%) followed by pain in neck region (83.2\%), upper back/thoracic region (80\%), right shoulder $(70.5 \%)$, headache (69.5\%), left shoulder (57.9\%), right lower extremity (52.6\%), right wrist (47.4\%), right hand (47.4\%), left lower extremity (42.1\%), left wrist (41.1\%), right elbow (37.4\%), left elbow (37.4\%), left hand $(34.7 \%)$ (Table 1.). No significant difference was found between males and females with respect to pain in these locations $(p>0.05)$.

The distribution of MS pain among different genders, age groups and working hours are tabulated in Table 2 to 4 . 
Humanshi Abbhi et.al. Prevalence and factors associated with musculoskeletal pain among dentists in Chandigarh: a cross sectional study.

Table 2. Distribution of MS pain among different genders

\begin{tabular}{|l|l|l|l|l|}
\hline S. No. & Gender & No. of subjects suffering & Total no of subjects & \% of subjects suffering \\
\hline 1. & Male & 30 & 43 & 69.8 \\
\hline 2. & Female & 65 & 77 & 84.4 \\
\hline Total & 95 & 120 & \\
\hline
\end{tabular}

Table 3. Distribution of MS pain in different age groups

\begin{tabular}{|l|l|l|l|l|}
\hline S.No. & Age group & No. of subjects suffering & Total no of subjects & \% of subjects suffering \\
\hline 1. & $<=30$ & 78 & 98 & 79.6 \\
\hline 2. & $>30$ & 17 & 32 & 77.3 \\
\hline Total & 95 & 120 & \\
\hline
\end{tabular}

Table 4. Distribution of MS pain among different groups according to working hours

\begin{tabular}{|l|l|l|l|l|}
\hline S.No & Working hours & No. of subjects affected & Total no. of subjects & \% of subjects affected \\
\hline 1. & Less than 3 hours & 2 & 3 & 66.7 \\
\hline 2. & 3-6 hours & 18 & 25 & 72 \\
\hline 3. & 6-9 hours & 49 & 65 & 75.4 \\
\hline 4. & More than 9 hours & 26 & 27 & 96.3 \\
\hline Total & 95 & 120 & \\
\hline
\end{tabular}

Although prevalence of pain was found to be more among females as compared to males and also higher in age group $<=30$ as compared to age group $>30$ but there was no significant difference between the groups with respect to pain ( $p=$ $0.058), \quad(p=0.809)$. Most of the dentists suffering from pain were those working for more than 9 hours followed by those working for 6-9 hours, 3-6 hours and less than 3 hours but no significant difference was found between different groups with respect to pain $(p=0.092)$. Hence forth, the study concluded that more work led to more strain on the body and hence more pain.

A remarkable percentage of dentists work by sitting in forward bending position and pain was found to be more among them (87.3\%). A significant difference was found among two groups (erect posture and forward bent posture $)(p=0.021)$. The distribution of MS pain among dentists and postures are represented in Table 5.

Table 5. Distribution of MS pain among dentists adopting different sitting postures

\begin{tabular}{|l|l|l|l|l|}
\hline S.No. & Sitting Posture & Number of subjects affected & Total no. of subjects & \% of subjects affected \\
\hline 1. & Erect Posture & 40 & 57 & $70.2 \%$ \\
\hline 2. & Forward bent posture & 55 & 63 & $87.3 \%$ \\
\hline \multicolumn{1}{|l|}{ Total } & 95 & 120 & \\
\hline
\end{tabular}

A significant association was found between years of practice and the MS pain $(p=0.035)$. Highest prevalence was found in those working for $>15$ years i.e. $90.9 \%$ followed by those working for 5-10 and less than 5 years but was found to be lowest among those working for 10-15 years. The distribution of MS pain among dentists and years of practice is represented in Table 6 .

Table 6. Distribution of MS pain among different groups according to years of practice

\begin{tabular}{|c|c|c|c|c|}
\hline S.No & Years of practice & No. of subjects affected & Total no. of subjects & $\%$ of subjects affected \\
\hline 1. & Less than 5 years & 36 & 50 & 72 \\
\hline 2. & $5-10$ & 42 & 47 & 89.4 \\
\hline 3. & $10-15$ & 7 & 12 & 58.3 \\
\hline 4. & More than 15 years & 10 & 11 & 90.9 \\
\hline & & 95 & 120 & \\
\hline
\end{tabular}

Among total dentists involved in the study $36.8 \%$ reported to feel discomfort after working for more than 3 hours, 30.5\% after 2-3 hours, $25.3 \%$ after 1-2 hours and $7.4 \%$ after less than 1 hour. Of the total participants $67.4 \%$ preferred some kind of activity to get some relief from the discomfort. The activity included normal range of motion exercises followed by $42.1 \%$ of dentists, stretching exercises by $20 \%$ and $5.3 \%$ of them preferred both (normal range of motion as well as 
stretching exercises). Most of the dentists felt $50 \%$ relief in their discomfort by doing these activities. Among all $20 \%$ of the dentists took sick leaves due to their discomfort. MS symptoms affected both work as well as leisure activity in $28.5 \%$ dentists whereas in $32.5 \%$ none of these activities were affected.

The results obtained in this study indicate the higher incidence of WMSDs among dentists. Among the professionals who took part in this survey, majority suffered from some or other kind of MS pain (79.2\%) during last 12 months. Our results were found to be comparable to those found in earlier studies done in Madhya Pradesh- $83.10 \%{ }^{(7)}$, Spain$79.8 \%{ }^{(2)}$, New South Wales- $82 \%{ }^{(8)}$ and Saudi Arabia- $83 \%^{(9)}$ but it was found to be lower than those found in the studies done in Australia - 87.2\%(10), China- $88 \%{ }^{(5)}$, Poland-92\% ${ }^{(11)}$ and higher than in study done in Thessaloniki, Greece- 62\% ${ }^{(12)}$.These findings could be due to forced, awkward and incorrect postures adopted by dentists during work or due to their prolonged working hours ${ }^{(13)}$. More than half of the subjects adopted forward bent posture in sitting position while working and also worked for longer duration which could be the reason for high prevalence of WMSDs.

Our findings of highest prevalence of pain in lower back region (87.4\%) followed by neck (83.2\%) was found to be consistent with studies already reported (7)(8)(14). Lalumandier et al. ${ }^{(15)}$ reported that all dental specialties show a high occurrence of musculoskeletal disorders, but variations in frequency and order in different locations.

In this particular survey it was found that females were more susceptible to pain than males which was same as seen in literature ${ }^{(2)(8)(9)}$. Some authors relate this difference to lesser muscle tone and higher incidence of osteoporosis among females ${ }^{(16)}$. Younger dentists were also found to have a higher incidence of pain in comparison to older dentists which was also found to be in accordance to some previous studies ${ }^{(2)(9)}$.
This might be attributed to incorrect working positions, since older dentists used more indirect vision and usually avoid neck overload ${ }^{(17)}$. Also younger dentists mainly practice general dentistry or were enrolled in postgraduate training which put them under more workload and psychosocial stress when compared to older dentists with specializations thereby having less load of patients ${ }^{(9)}$.

Coinciding with previous study (17) no significant association was found between daily working hours and the MS pain. Highest prevalence of pain was seen in dentists working for more than 9 hours daily followed by those working for 6-9, 3-6 and less than 3 hours. This could be due to longer working hours because of increased workload which in turn increases the prevalence of pain with increase in working hours.

A significant association was found between sitting posture adopted by dentists and the MS pain. Highest prevalence was found in dentists adopting forward bent posture during work (87.3\%) which was consistent with the findings of Jabbar et $a l^{(9)}$ These might be due to increase in strain on muscles during the abnormal posture and the biomechanical changes as a result of this posture.

No significant association was found between the posture adopted while working in standing position and MS pain. Although highest prevalence of pain (85.7\%) was found in dentists adopting forward bent posture while standing and it could be due to increase in strain on muscles.

A significant association was found between years of practice and the MS pain. Highest prevalence was found in those working for $>15$ years followed by those working for 5-10 and less than 5 years but was found to be lowest among those working for 10-15 years. The reason for this high prevalence with increase in age may be that over months and years, the body adapts to the abnormal posture caused by these muscles and imbalances and maintains this unbalanced posture at work which leads to 
physiological changes in body. The explanation for the lowest prevalence among the group of dentists working for 1015 years might be the more observational work for their juniors (less than 5 or 5-10) as compared to physical workload which could likely decrease the prevalence of pain among this group. Moreover, they start to keep fit and work less intensively as compared to younger dentists.

\section{Impact of WMSD on work:}

Twenty percent of the subjects reported to have taken sick leaves due to WMSD. This finding was found to be consistent with the findings of some earlier studies $^{(10)(12)}$.

Twenty percent of the subjects had sought some kind of treatment for their WMSD. This finding was consistent with the findings of Alexopolous EC et al. ${ }^{(12)}$ and Leggat PA et al. ${ }^{(10)}$. The treatment included physiotherapy (10.8\%), analgesics (5.8\%) and muscle relaxants (3.3\%).

The study revealed that the prevalence of MS pain was high among dentists in Chandigarh. Higher incidence of pain was found in women and younger dentists. The lower back region was most affected area followed by neck region. Also found that WMSD increased with increase in years of practice with significant association between them. Additionally, the abnormal posture increased the incidence of pain. However, these disorders were not associated with patient's demographics.

The study suggested that the implementation of preventive measures is necessary in view of the high prevalence of these disorders. Further studies must be done to analyze the preventive strategies which should focus on ergonomics, breaks at work, general health and physical exercise.

\section{CONCLUSION}

The study reveals that the prevalence of MS pain is high among dentists in Chandigarh. Higher incidence of pain is found in women and younger dentists. The lower back region is most commonly affected area followed by neck region. The study also found that WMSD increased with increase in years of practice with significant association between them. It also showed that adoption of abnormal posture increases the incidence of pain. However, these disorders were not associated with patient's demographics.

\section{Acknowledgement: None}

\section{Conflict of Interest: None}

\section{Source of Funding: None}

\section{Ethical Approval: Approved}

\section{REFERENCES}

1. Lehto TU, Helenius HY, Alaranta HT. Musculoskeletal symptoms of dentists assessed by a multidisciplinary approach. Comm Dent Oral Epidemiol. 1991;19:3844.

2. Harutunian K, Gargallo-Albiol J, Figueiredo R, Gay-Escoda C. Ergonomics and musculoskeletal pain among postgraduate students and faculty members of the school of dentistry of the university of Barcelona (Spain). A cross-sectional study. Med Oral Pathol Oral Cir Bucal. 2011;16:e425-e429.

3. Damkot DK, Pope MH, Lord J, Frymoyer JW. The relationship between work history, work environment and low back pain in men. Spine. 1984;9:395-399.

4. Sarkar PA, Shigli AL. Ergonomics in general dental practice. People's J Sci Res. 2012;5:56-60.

5. Feng B, Liang Q, Wang Y. Prevalence of work-related musculoskeletal symptoms of neck and upper extremity among dentists in China. BMJ Open. 2014;4:e006451.

6. Valachi B, Valachi K. Mechanisms leading to musculoskeletal disorders in dentistry. J Am Dent Assoc. 2003;134:1344-1350.

7. Saxena P, Gupta SK, Jain S, Jain D. Workrelated musculoskeletal pain among dentists in Madhya Pradesh, India: prevalence, associated risk factors and preventive measures. Asia Pac J of Public Health. 2014; 26:1-6.

8. Marshall ED, Duncombe LM, Robinson RQ, Kilbreath SL. Musculoskeletal 
Humanshi Abbhi et.al. Prevalence and factors associated with musculoskeletal pain among dentists in Chandigarh: a cross sectional study.

symptoms in New South Wales dentists. Aust Dent J. 1997;42:240-246 .

9. Abdul Jabbar TA. Musculoskeletal disorders among dentists in Saudi Arabia. Pak Oral Dent J. 2008;28:135-144.

10. Leggat PA, Smith DR. Musculoskeletal disorders self-reported by dentists in Queensland, Australia. Aust Dent J. 2006; 51:324-327.

11. Kierklo A, Kobus A, Jaworska M, Botulinski B. Work-related musculoskeletal disorders among dentists-A questionnaire survey. Ann Agric Environ Med. 2011; 18:79-84.

12. Alexopoulos EC, Stathi IC, Charizani F, Prevalence of musculoskeletal disorders in dentists. BMC MusculoskeletDisord. 2004; 5:1-8.

13. Powell M, Eccles JD. The health and work of two professional groups: Dentists and pharmacists. Dent Practit.1970;20:373-378.

14. Ratzon NZ, Yaros T, Mizlik A, Kanner T, Musculoskeletal symptoms among dentists in relation to work posture. Work. 2000; 15:153-158.

15. Lalumandier JA, Mcphee SD, Paarrott CB, Vendemia M. Musculoskeletal pain: prevalence, prevention and differences among dental office personnel. Gen Dent. 2001;49:160-166.

16. Lehto TU, Ronnemaa TE, Aalto TV, Helenius HY. Roentgenological arthrosis of the hand in dentists with reference to manual function. Commu Dent Oral Epidemiol. 1990;18:37-41

17. Rundcranz B.L., Johnsson B., Moritz U.: Cervical pain and discomfort among dentists. Epidemiological, clinical and therapeutic aspects. Swed Dent J. 1990; $14: 71-80$

How to cite this article: Abbhi H, Sarkar P, Ramasubbu $\mathrm{H}$ et.al. Prevalence and factors associated with musculoskeletal pain among dentists in Chandigarh: a cross sectional study. Int J Health Sci Res. 2021; 11(11): 244-251. DOI: https://doi.org/10.52403/ijhsr.20211129 